\title{
Tumor fibroso solitario de la próstata
}

\section{Solitary fibrous tumor of the prostate}

\section{Sr. Director:}

Se trata de un paciente de 65 años con obstrucción urinaria de 6 meses de evolución. El examen digital prostático rectal mostró la próstata de consistencia fibroelástica, sin nódulos. El nivel sérico del antígeno prostático (AP) total era de
7,52 ng/ml, el AP libre de 2,61 ng/ml, con un ratio de 0,35. El ultrasonido abdominopélvico confirmó la presencia de agrandamiento prostático. El diagnóstico clínico fue de hiperplasia prostática benigna grado I-II. Se realizó una prostatectomía suprapúbica por la técnica de Millin. Después de que se llevara 

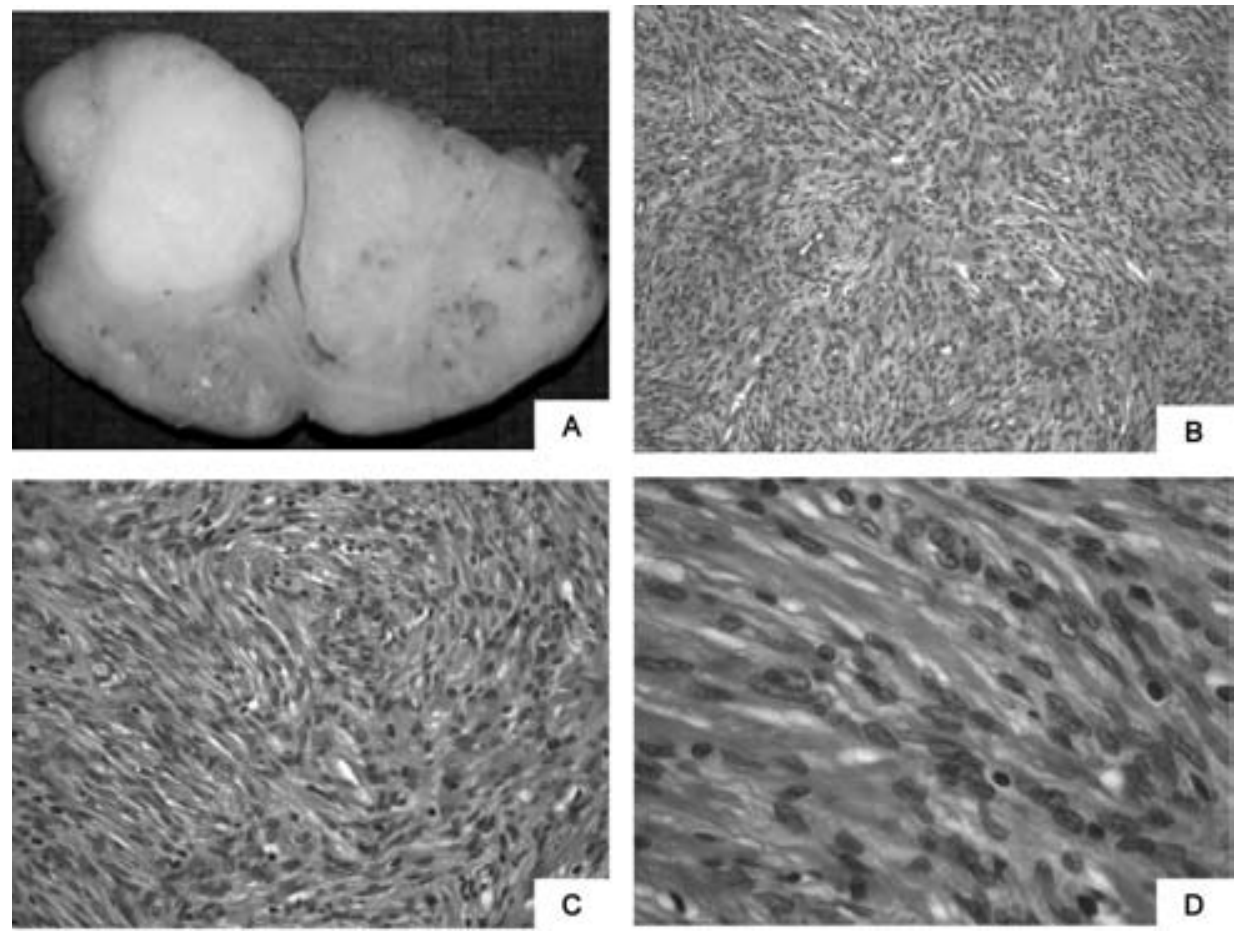

Figura 1- (A) Aspecto macroscópico del tumor fibroso solitario (TFS) de la próstata. Se evidencia un tumor bien definido, sin hemorragia ni necrosis; compárese el tejido prostático adyacente al tumor. (B) Aspecto histopatológico característico de un TFS, mostrando áreas hipercelulares (hematoxilina-eosina [H-E] x40). (C) La vasculatura era predominantemente de vasos capilares pequeños (H-E, x100). (D) El tumor estaba caracterizado por una proliferación de células fusiformes dispuestas al azar con focos de depósito de colágeno intercelular (H-E, x400).
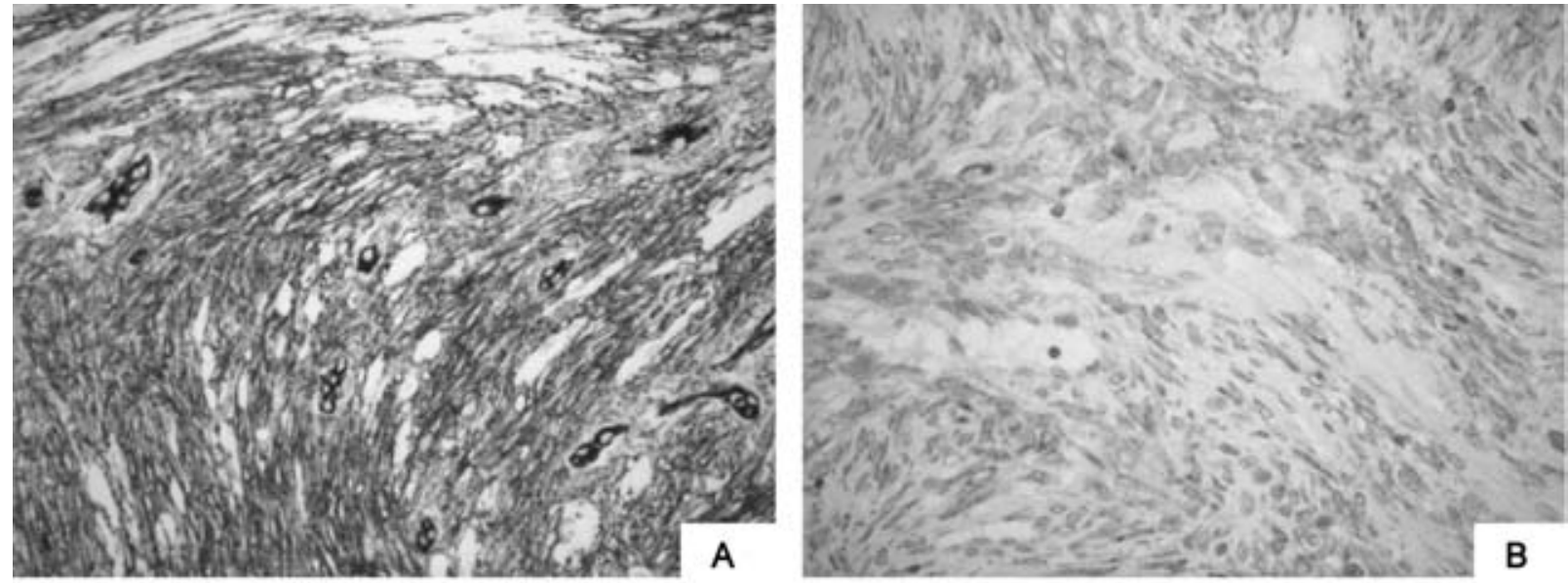

Figura 2- Estudios inmunohistoquímicos. (A), (B) y (C) CD34, BCL-2 y CD99 mostrando positividad en el citoplasma y la membrana plasmática de las células tumorales (diaminobencidina [DAB], x200). (D) Expresión nuclear de Ki-67 (DAB, x200).

a cabo el procedimiento quirúrgico, el espécimen fue enviado para estudio histopatológico. El espécimen de adenomectomía fue fijado en formol tamponado al $10 \%$, y procesado para su estudio histopatológico e inmunohistoquímico de manera usual. Macroscópicamente, la muestra era irregular de 80 x 65 x $24 \mathrm{~mm}$, rosada con áreas pardas. La superficie de corte era multinodular, con un nódulo bien definido, blanco grisáceo, homogéneo. No se observaron zonas de necrosis ni de hemorragia (fig. 1). Histopatológicamente, el tumor estaba constituido por células fusiformes cortas, distribuidas al azar, con 
núcleos redondeados u ovoides, con cromotatina distribuida de forma homogénea y nucléolos inconspicuos (fig. 1). La vasculatura predominante era de vasos capilares pequeños. En la periferia del tumor el componente epitelial prostático normal se encontraba atrapado por la proliferación mesenquimal. No se evidenciaron mitosis, hemorragia, cambios mixoides ni necrosis. Las células neoplásicas mostraron positividad para el CD34, CD99 y la oncoproteína BCl-2 (fig. 2). La tasa de proliferación celular, medida a través de la expresión nuclear de $\mathrm{Ki}-67$, fue de un 17\%.

El tumor fibroso solitario (TFS) es una neoplasia prostática infrecuente, con al menos 20 casos descritos en la literatura ${ }^{1}$. La presentación clínica del TFS cuando afecta la próstata es variable, dependiendo principalmente del tamaño tumoral y de la afectación de estructuras adyacentes $^{2,3}$. Los casos previamente informados se han presentado con síntomas urinarios bajos, los cuales varían desde disuria hasta retención urinaria aguda ${ }^{2-4}$. Nuestro paciente no mostró síntomas específicos, probablemente debido a la localización central de la neoplasia. A causa de la variabilidad del TFS en el estudio microscópico, un espectro de otros tumores deben incluirse en el diagnóstico diferencial de esta neoplasia. Así, en la próstata el TFS debe ser distinguido de varias proliferaciones mesenquimáticas benignas y malignas, pero dos son las más importantes dadas sus implicaciones pronósticas y predictivas, como son el carcinoma sarcomatoide y el tumor del estroma gastrointestinal (GIST). Generalmente, el carcinoma sarcomatoide muestra características histopatológicamente atípicas y con expresión de citoqueratinas de amplio espectro ${ }^{3}$. Por su parte, los GIST pueden ser distinguidos de los TFS dada la expresión de c-Kit por parte de los GIST ${ }^{5}$.

El origen de los TFS de la próstata es desconocido. En diferentes tejidos se han documentado células similares a fibroblastos CD34 positivos, en el mesénquima, en especial alrededor de estructuras vasculares, neurales, etc. ${ }^{6}$. Un número de lesiones positivas para el CD34, como el dermatofibrosarcoma protuberans en la piel ${ }^{7}$, los pólipos fibroides intestinales ${ }^{8}$, se desarrollan en lugares en los cuales hay poblaciones normales de células similares a fibroblastos CD34 positivos. Tomando en consideración estos hallazgos se ha sugerido que estas lesiones pudieran desarrollarse a partir de células similares a fibroblastos CD34 positivas. Curiosamente, los informes previos, al igual que en nuestro caso, describen una intensa expresión para el CD34 ${ }^{1-4}$. Probablemente este hallazgo sugiera que el componente proliferativo fusiforme de estas lesiones se desarrrolla a partir de células intersticiales CD34 positivas, de una manera similar a lo propuesto en otras lesiones CD34 positivas de otras localizaciones.

En conclusión, presentamos un típico caso de un TFS de la próstata. La cirugía local es a menudo suficiente como tratamiento. Probablemente, el origen histogenético en la próstata sea las células fibroblásticas CD34 positivas.

\section{B I B L I O G R A F Í A}

1. Westra WH, Grenko RT, Epstein J. Solitary fibrous tumor of the lower urogenital tract: a report of five cases involving the seminal vesicles, urinary bladder, and prostate. Hum Pathol. 2000;31:63-8.

2. Pacios Cantero JC, Alonso Dorrego JM, Cansino Alcalde JR, de La Peña Barthel JJ. Tumor fibroso solitario de la próstata. Actas Urol Esp. 2005;29:985-8.

3. Herawi M, Epstein JI. Solitary fibrous tumor on needle biopsy and transurethral resection of the prostate.

A clinicopathologic study of 13 cases. Am J Surg Pathol. 2007;31:870-6.

4. Grasso M, Blanco F, Franzoso C, Lania C, Di Bella C, Crippa S. Solitary fibrous tumor of the prostate. J Urol. 2002;168:1100.

5. Herawi M, Montgomery E, Epstein JI. Gastrointestinal stromal tumors (GISTs) on prostatic needle biopsy. Am J Surg Pathol. 2006;30:1389-95.

6. Nickoloff BJ. The human progenitor cell antigen (CD34) is localized on endothelial cells, dermal dendritic cells, and perifollicular cells in formalin-fixed normal skin, and on proliferating endothelial cells and stromal spindle-shaped cells in Kaposi's sarcoma. Arch Dermatol. 1991;127:523-9.

7. Aiba S, Tabata $\mathrm{N}$, Ishii $\mathrm{H}$, Ootani $\mathrm{H}$, Tagami $\mathrm{H}$. Dermatofibrosarcoma protuberans is a unique fibrohistiocytic tumour expressing CD34. Br J Dermatol. 1992;127:79-84.

8. Wille P, Borchard F. Fibroid polyps of intestinal tract are inflammatory-reactive proliferations of CD34-positive perivascular cells. Histopathology. 1998;32:498-502.

D. Parada Domínguez*, K.B. Peña González, V. Morente Laguna y F. Riu Ferrando

Servei de Anatomia Patológica, Hospital Universitario de Sant Joan, Reus. Institut d’Investigació Sanitaria Pere Virgili (IISPV), Universitat Rovira i Virgill, Reus, Tarragona, España

*Autor para correspondencia. Correo electrónico: dparada@grupsagessa.com (D. Parada Domínguez) 